\title{
Vitamin D with asthma and COPD: not a false hope? A systematic review and meta-analysis
}

\author{
L.L. Zhang ${ }^{1}$, J. Gong ${ }^{2}$ and C.T. Liu ${ }^{1,3}$ \\ ${ }^{1}$ Department of Respiratory Medicine, West China Hospital, \\ Sichuan University, Chengdu, Sichuan, China \\ ${ }^{2}$ Departments of Obstetrics/Gynecology, West China Second Hospital, \\ Chengdu, Sichuan, China \\ ${ }^{3}$ Department of Good Clinical Practice, West China Hospital, \\ Sichuan University, Chengdu, Sichuan, China \\ Corresponding author: C.T. Liu \\ E-mail: zll280831@163.com
}

Genet. Mol. Res. 13 (3): 7607-7616 (2014)

Received March 25, 2013

Accepted September 25, 2013

Published February 13, 2014

DOI http://dx.doi.org/10.4238/2014.February.13.10

\begin{abstract}
Vitamin D deficiency and insufficiency are increasingly being recognized in the general population over the last few decades. However, a number of other disorders have now been linked to vitamin D deficiency and insufficiency, including asthma and COPD. The aim of this study was to evaluate the evidence on the effect of vitamin D on asthma and COPD. We searched electronic databases including SCI, EMBASE, Ovid, and PubMed. Reviewers working independently and in duplicate extracted study characteristics, quality, and the outcomes. The weighted mean differences across trials and random-effect meta-analysis were used to pool the relative risks (RR). This is the first meta-analysis about the risk of vitamin $\mathrm{D}$ deficiency for asthma and COPD. Ten studies were available for this meta-analysis and systematic review. The prevalence of vitamin D deficiency was significantly greater among cases than control subjects $[\mathrm{RR}=1.59,95 \% \mathrm{CI}=1.07-2.36,488 / 812(60 \%)$ vs $278 / 875(32 \%)]$ for asthma. However, vitamin D insufficiency was not significantly associated with asthma $[\mathrm{RR}=1.09,95 \% \mathrm{CI}=0.91-1.30,702 / 996(70 \%)$ vs $665 / 1016$
\end{abstract}


$(65 \%)]$. Moreover, studies failed to demonstrate that COPD patients had an increased risk for vitamin D deficiency or insufficiency compared to controls $(\mathrm{RR}=0.89,95 \% \mathrm{CI}=0.63-1.25)$. Vitamin $\mathrm{D}$ deficiency was associated with a significant decrease in lung function in asthmatic children. Vitamin D deficiency was highly prevalent in asthma patients, and vitamin D status was associated with lung function. COPD cannot be considered as completely free of vitamin D deficiency.

Key words: Systematic review; Meta-analysis; COPD; Asthma; Vitamin D deficiency; Vitamin D insufficiency

\section{INTRODUCTION}

As many as 300 million people of all ages, and all ethnic backgrounds suffer from asthma, and the burden of this disease to governments, health care systems, families, and patients is increasing worldwide (Masoli et al., 2004). Asthma and COPD (chronic obstructive pulmonary disease) in every stage of severity are very prevalent diseases and represent a substantial burden on health care resources in all countries so far studied (Masoli et al., 2004). The costs of asthma and COPD are largely due to uncontrolled disease, and are likely to rise as their prevalence and severity increase. Asthma and COPD are chronic respiratory diseases characterized by heightened airway inflammation, airway hyper-responsiveness and airflow obstruction to specific triggers (Contoli et al., 2010). In recent years, there has been growing evidence to suggest that vitamin D plays an important role in inflammation (Zasloff, 2006). Vitamin D can suppress Th2-mediated allergic airway disease and may modulate the suppressive activity of local regulatory cells (Gorman et al., 2010), and vitamin D also plays a key role in the regulation of immune function (Hewison, 2012; Ooi et al., 2012).

The role of vitamin D in calcium and bone homeostasis has been well described, and vitamin D's relation to infection, cancer, cardiovascular disease has been recognized in the last years (Garland et al., 1985; Schwartz and Hulka, 1990; McGrath, 1999; McGrath et al., 2004; Wang et al., 2008). The underlying mechanisms how vitamin D metabolism could be linked to the pathophysiology of asthma and COPD are often complex and not fully understood (Paul et al., 2012). Vitamin D deficiency and asthma are common conditions that share risk factors such as African American ethnicity, inner-city residence, and obesity.

However, whether COPD and asthma patients actually have a higher prevalence of vitamin D deficiency than controls is not yet well established. Some reviews and studies have not confirmed a positive association between blood vitamin D and asthma and COPD. Some have supported the notion that vitamin D is not associated with asthma or COPD (Schauber and Gallo, 2008; Camargo et al., 2011; Shaheen et al., 2011; Krobtrakulchai et al., 2012), but some have an opposite opinion (Li et al., 2011; Chinellato et al., 2011; Goleva et al., 2012).

\section{MATERIAL AND METHODS}

\section{Definition of vitamin D level}

We divided subjects into vitamin D deficiency $(<20 \mathrm{ng} / \mathrm{mL})$, insufficiency $(<30 \mathrm{ng} /$ $\mathrm{mL})$, and sufficiency (>30 $\mathrm{ng} / \mathrm{mL})$ groups. 


\section{Studies and interventions and inclusion and exclusion criteria}

We included studies with data on the study group of asthma and COPD and in a control group of non-asthmatics and non-COPD: 7 studies were in children (Brehm et al., 2010; Freishtat et al., 2010; Rothers et al., 2011; Alyasin et al., 2011; Bener et al., 2012; Brehm et al., 2012; Goleva et al., 2012); 3 studies were with adults (Li et al., 2011; Persson et al., 2012; Zhou et al., 2012); 2 studies were on COPD (Persson et al., 2012; Zhou et al., 2012), and 8 studies on asthma. Studies without a control group were excluded. Studies including different outcome (e.g., both asthma and COPD) were also excluded, if the outcomes were not reported separately.

\section{Retrieval of studies and data extraction}

A systematic search was performed from 1989 until June 2013 in PubMed, EMBASE and Cochrane Collaboration containing the following key words: chronic obstructive pulmonary disease, COPD, asthma, and vitamin $\mathrm{D}$.

\section{Statistical analysis}

We used a random-effect model to pool relative risk (RR). A P value less than 0.05 was considered to be statistically significant. We assessed heterogeneity between studies with the Cochrane $\mathrm{I}^{2}$ test and evaluated the percentage of total variation across studies caused by heterogeneity with the groups for studies that contributed data for multiple procedures. $\mathrm{I}^{2}$ is the proportion of total variation contributed by between-study variation. In general, $\mathrm{I}^{2}$ values greater than $60-70 \%$ indicate the presence of substantial heterogeneity. We assessed potential publication bias using formal tests, namely funnel's plot and the Egger test (Egger et al., 1997). As outcomes are rare (for instance, the incidence is less than $1 \%$ and several studies have no events in one of the comparison groups), the pooled RR can be unstable and influenced by the chosen continuity correction and pooling method (DerSimonian and Laird, 1986; Higgins et al., 2003). To test robustness, we applied several alternative methods for pooling (fixed- and random-effect models), weighting of the study estimates (MantelHaenszel, reciprocal of the variance), and continuity correction values. We used Review Manager 5 for statistical evaluation.

\section{RESULTS}

\section{Study characteristics}

The electronic database searches identified 3153 citations. After evaluating these citations, review articles, and the bibliographies of included studies, we included 10 trials (Figure 1).

Table 1 describes the characteristics of the studies included ranked by year of publication, asthma in 8 studies, COPD in 2 studies. Most included studies concerning retrospective cohorts; only one study (Rothers et al., 2011) included a prospective cohort. Other studies selected a control population after matching/adjusting each asthma patient for several potential confounding factors such as age, gender, race, ethnicity, seasonality, and BMI (Table 1). 


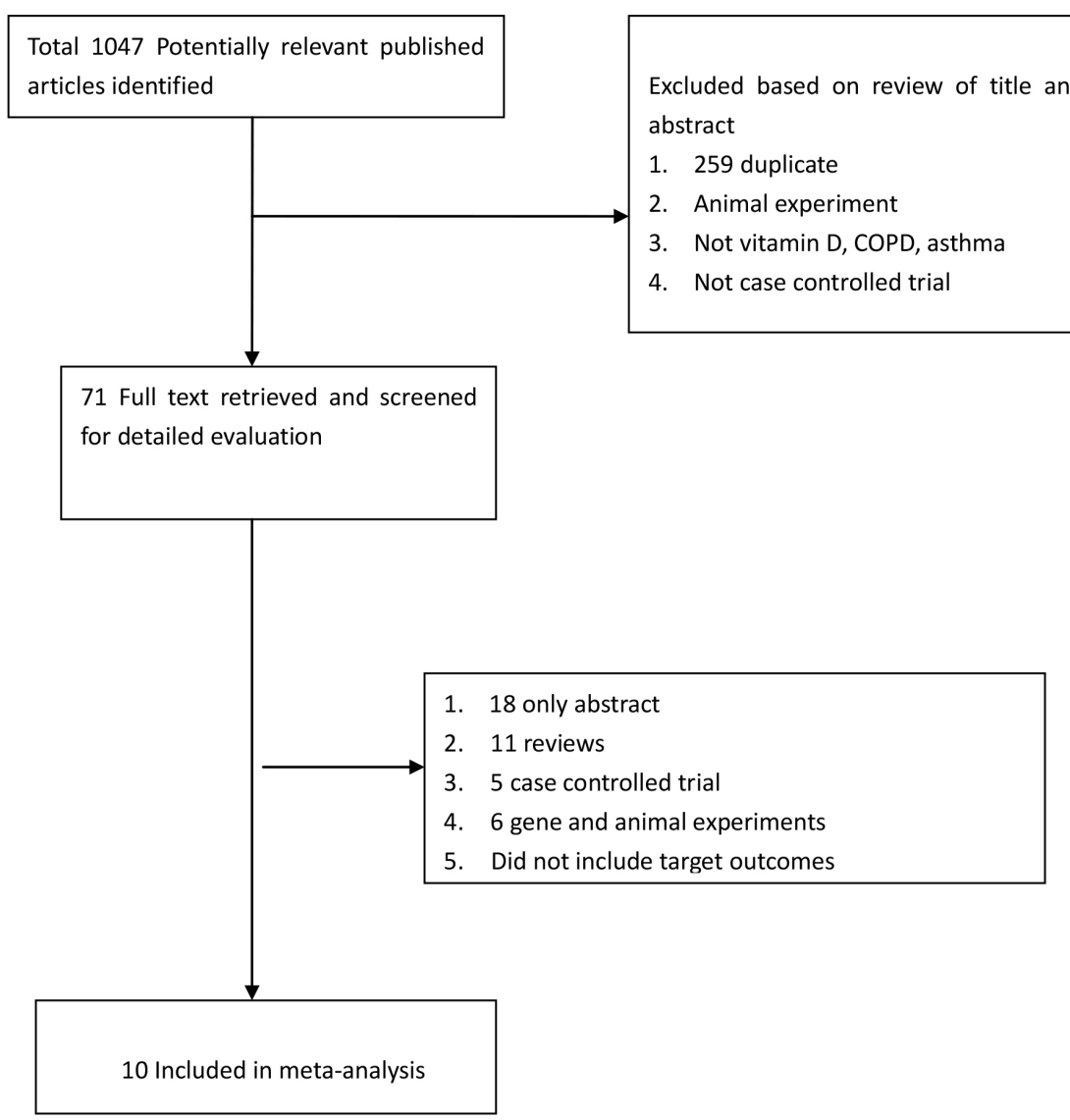

Figure 1. Flow of study selection.

\section{Asthma}

Figure 2A, B, C shows that the variation in RR for vitamin $\mathrm{D}<20$ and $<30 \mathrm{ng} / \mathrm{mL}$ in deficiency and insufficiency group and control group. Despite heterogeneity between procedures, we still showed an overall pooled RR.

Inter-study heterogeneity was seen for vitamin $\mathrm{D}<30 \mathrm{ng} / \mathrm{mL}(\mathrm{RR}=1.09,95 \%$ confidence interval $(\mathrm{CI})=0.91-1.30 ; \mathrm{P}=0.34 ; \mathrm{I}^{2}=71 \%$ ). A study by Freishtat et al. (2010) showed huge increases $(\mathrm{RR}=4.51,95 \% \mathrm{CI}=1.86-10.93)$. Omission of this outlying study yielded a pooled $\mathrm{RR}$ that was not significantly different from unity $(\mathrm{RR}=1.03,95 \% \mathrm{CI}=0.93-1.15)$ (Figure 2A). The reason for this outlying result is not clear and could have been due to the study design mentioned earlier. The risk associated with vitamin $\mathrm{D}<20 \mathrm{ng} / \mathrm{mL}$ was $\mathrm{RR}=1.59$ with $95 \% \mathrm{CI}=1.07-2.36\left(\mathrm{I}^{2}=75 \%\right)$. A study by Rothers et al. (2011) showed no increase $(0.63$ [0.27-1.46]) and another showed a substantial increase and reach significance (1.59 [1.072.36]) (Figure 2B).

Vitamin $\mathrm{D}<10 \mathrm{ng} / \mathrm{mL}$, described in only one study, was also followed by a significantly increased chance of asthma (2.40 [1.78-3.22]) (Figure 2C). 
Vitamin D and asthma

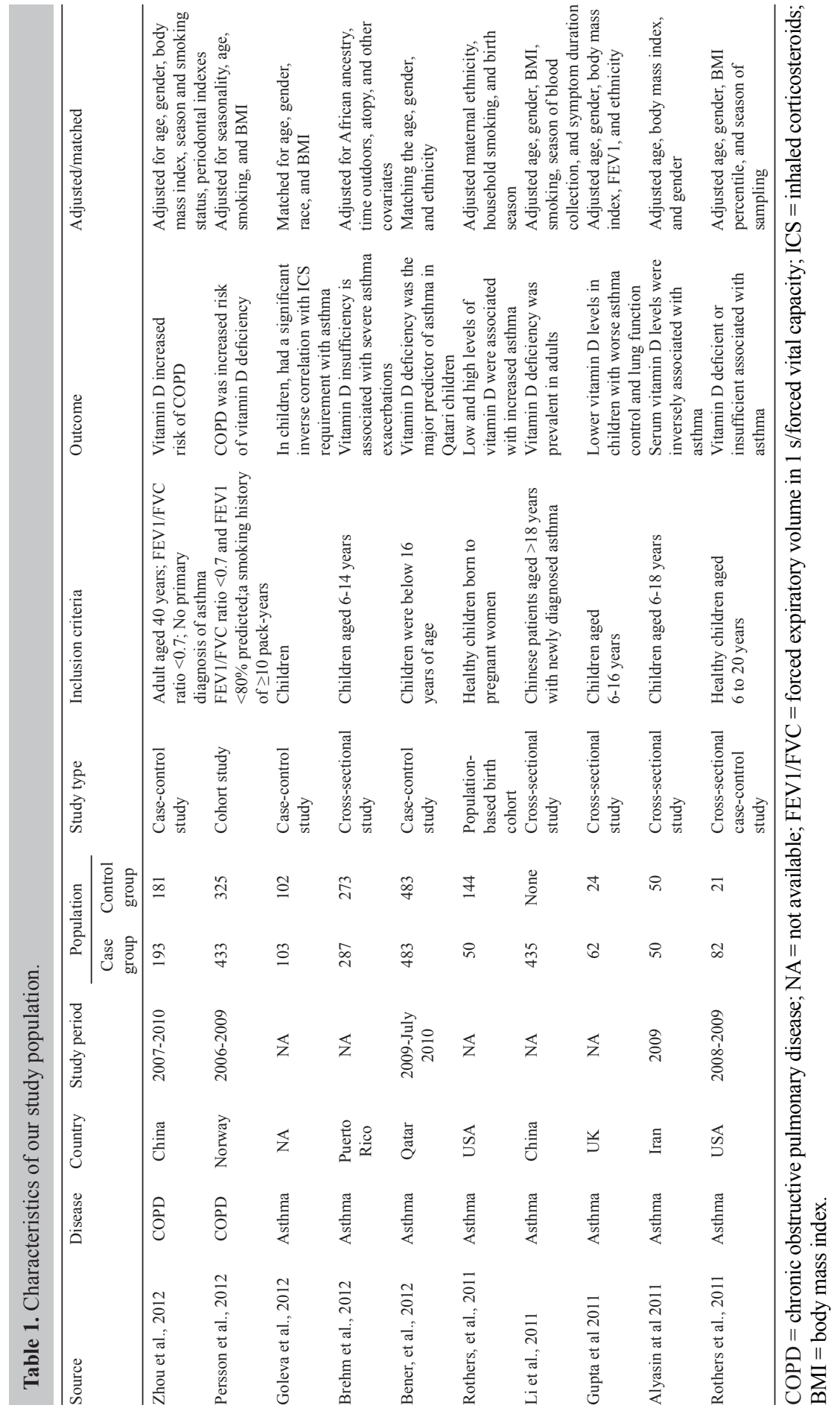






Figure 2. Relative risk for vitamin $\mathrm{D}<20$ and $<30 \mathrm{ng} / \mathrm{mL}$ in deficiency and insufficiency group and control group. A. Vitamin D $<30 \mathrm{ng} / \mathrm{mL}$. B. Omission of one study. C. Vitamin D $<20 \mathrm{ng} / \mathrm{mL}$. D. Vitamin D $<10 \mathrm{ng} / \mathrm{mL}$.

\section{Lung function}

Two investigators also described FEV1\% with a positive association between lower vitamin $\mathrm{D}(<20 \mathrm{ng} / \mathrm{mL})$ and higher vitamin $\mathrm{D}(>40 \mathrm{ng} / \mathrm{mL})(\mathrm{WMD}=-10.03[-11.01$ to -9.05$])$ (Figure 3A), and FEV1/FVC\% (WMD = -5.31 [-5.65 to -4.96]) (Figure 3B). Both of them were associated with a significant decrease in lung function in asthmatic children. Although 
our study did not have strong enough power to confirm or exclude a definite decrease in lung function, lung function was consistently decreased in the study group. According to Wu et al. (2012), vitamin D deficiency is associated with poorer lung function in children with vitamin $\mathrm{D}$ insufficiency or sufficiency. They corroborated the suggestion that vitamin D deficiency is a potential risk in some patients.

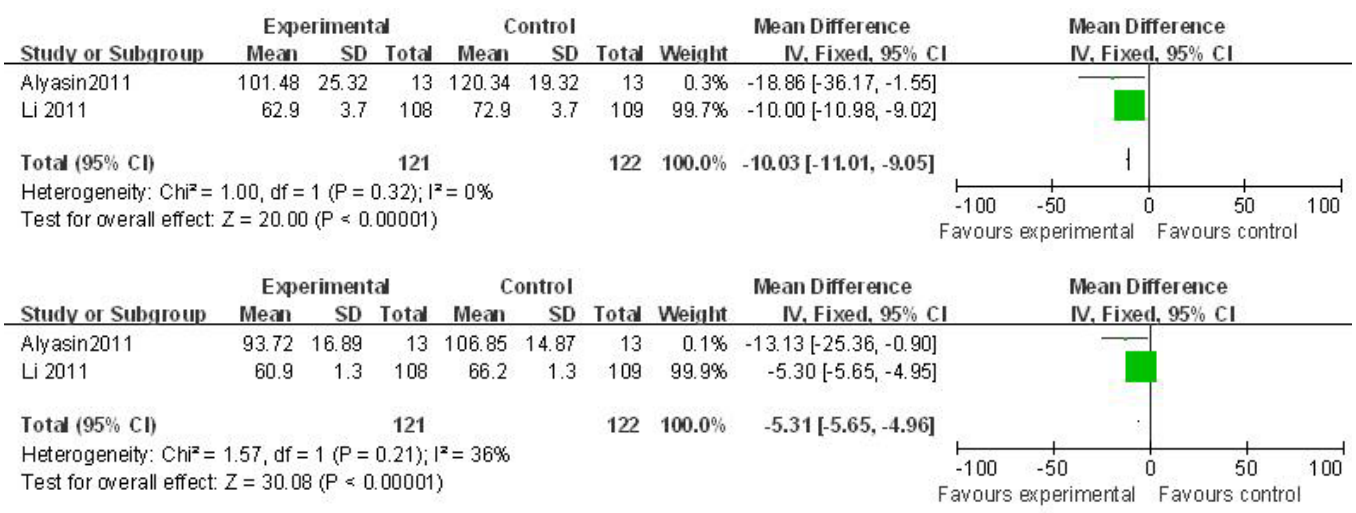

Figure 3. Association of FEV1 and FEV1/FVC between lower vitamin D $(<20 \mathrm{ng} / \mathrm{mL})$ and higher vitamin D $(>40$ $\mathrm{ng} / \mathrm{mL})$. A. FEV1 vitamin $\mathrm{D}<20 \mathrm{ng} / \mathrm{mL}$ compared with vitamin $\mathrm{D}>40 \mathrm{ng} / \mathrm{mL}$. B. FEV1/FVC vitamin D $<20 \mathrm{ng} /$ $\mathrm{mL}$ compared with vitamin $\mathrm{D}>40 \mathrm{ng} / \mathrm{mL}$.

\section{Exacerbations}

Children with vitamin D levels $<30 \mathrm{ng} / \mathrm{mL}$ were more likely to have severe asthma exacerbations over the course of the 4-year trial (OR $=1.76$ [1.01-3.09]) (Litonjua et al., 2008).

\section{COPD}

Two studies (Persson et al., 2012; Zhou et al., 2012) showed that the prevalence of vitamin D insufficiency and deficiency was not significantly different between cases and control subjects $\left(\mathrm{RR}=0.89[0.63-1.25], \mathrm{P}=0.5 ; \mathrm{I}^{2}=25 \%\right)$ (Figure 4).

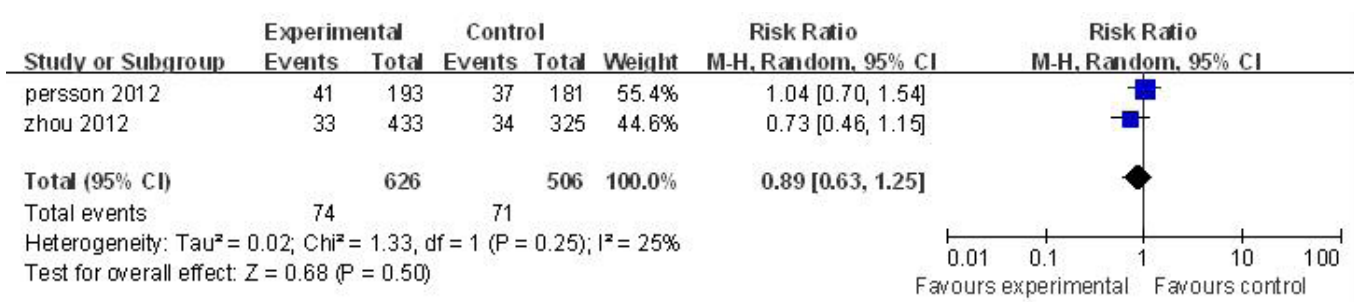

Figure 4. Chronic obstructive pulmonary disease $<25 \mathrm{ng} / \mathrm{mL}$.

\section{Intervention}

There were 2 randomized, placebo-controlled trials that showed the effects of vitamin D 
on asthma and COPD (Schou et al., 2003; Lehouck et al., 2012) (Table 2). The exacerbations did not significantly differ between the groups (including the median time to first exacerbation, exacerbation rates), nor did FEV1 and PEF (peak expiratory flow). However, Lehouck et al. (2012) showed that a severe vitamin $\mathrm{D}$ deficiency $(<10 \mathrm{ng} / \mathrm{mL})$ at baseline displayed a significant reduction in exacerbations in the vitamin $\mathrm{D}$ group $(\mathrm{RR}=0.57$ [0.33-0.98], $\mathrm{P}<0.042)$.

Table 2. Effects of vitamin D on asthma and chronic obstructive pulmonary disease (COPD).

\begin{tabular}{|c|c|c|}
\hline Type & Asthma (Schou et al., 2003) & COPD (Lehouck et al., 2012) \\
\hline Patients & $\begin{array}{l}\text { Children with asthma treated with inhaled dry-powder } \\
\text { budesonide } 400 \mathrm{mg} \text { daily }\end{array}$ & $\begin{array}{l}182 \text { patients with moderate to very severe COPD and a history of recent } \\
\text { exacerbations }\end{array}$ \\
\hline Interventions & $\begin{array}{l}15 \mathrm{mg}(600 \mathrm{IU}) 25-\mathrm{OH} \text {-vitamin D once daily in the } \\
\text { morning with run-in and washout periods of } 2 \text { weeks } \\
\text { and treatment periods of } 4 \text {-week duration. }\end{array}$ & $\begin{array}{l}100,000 \text { IU vitamin D supplementation or placebo every } 4 \text { weeks for } \\
1 \text { year }\end{array}$ \\
\hline FEV1 & $\mathrm{P}=0.60$ & $\mathrm{P}=0.95$ \\
\hline PEF (morning) & $\mathrm{P}=0.84$ & NA \\
\hline PEF (evening) & $\mathrm{P}=0.79$ & NA \\
\hline \multirow[t]{3}{*}{ exacerbations } & NA & Annual rate of exacerbations $0.94(\mathrm{CI}=0.76$ to 1.16$) ; \mathrm{P}=0.57$ \\
\hline & NA & Time to first exacerbation: hazard ratio $=1.1(\mathrm{CI}=0.82$ to 1.56$) ; \mathrm{P}=0.41$ \\
\hline & NA & $\begin{array}{l}\text { Vitamin D levels }<10 \mathrm{ng} / \mathrm{mL} \text { exacerbation rate ratio }=0.57(\mathrm{CI}=0.33 \text { to } \\
0.98) ; \mathrm{P}<0.042\end{array}$ \\
\hline
\end{tabular}

$\mathrm{FEV} 1=$ forced expiratory volume in $1 \mathrm{~s} ; \mathrm{PEF}=$ peak expiratory flow; $\mathrm{NA}=$ not available.

\section{DISCUSSION}

This is the first meta-analysis covering the relationship of vitamin D to asthma and COPD. We compared serum vitamin D levels in asthmatic and COPD subjects with those in a healthy control group. Although we observed a higher prevalence of vitamin D insufficiency and deficiency in asthmatic children, this difference was not statistically significant. We also further demonstrated that vitamin D insufficiency at baseline is associated prospectively with increased odds of severe asthma exacerbations. In addition, children with insufficient vitamin D levels have a slightly lower mean FEV1 compared with children with sufficient levels. Moreover, COPD patients have an increased risk for having vitamin D deficiency. However, vitamin $\mathrm{D}$ in addition to regular therapy does not reduce exacerbation and increase lung function, such as FEV1 and PEF.

Our study has its limitations. Due to lack of data on exacerbations from all studies, our pooled results were likely underpowered to get a significant difference in exacerbations. Second, the choice of entry criteria could be perceived as a limitation of our study. Some early clinical trials of subjects showed deficiency consistent with substantial reductions in lung function or exacerbations, but failed to demonstrate significant clinical or functional improvement in pooled results.

\section{Biological mechanisms}

Several proposed mechanisms may be considered about vitamin D deficiency worsening COPD and asthma. The first is anti-microbial effects. There is evidence from epidemiological studies that vitamin D deficiency is a risk factor for respiratory infection (Urashima et al., 2010; Camargo et al., 2011). Vitamin D insufficiency may contribute to chronic respiratory infections and airway colonization (Zasloff, 2006). The second is lung tissue remodeling. Indirectly or directly, vitamin D regulates extracellular matrix homeostasis in tissues other than 
bone, within particular lung and skin tissue via the control of transforming growth factor-b, matrix metalloproteinase and plasminogen activator systems (Boyan et al., 2007). Immune modulation and peripheral muscle function should also be considered. Periodontitis, which is an infectious disease correlated with vitamin D deficiency, may intensify the pathogenesis of COPD. Third, it is challenging to propound a unifying hypothesis to account for airway smooth muscle changes being the sole manifestation of vitamin D deficiency (Gupta et al., 2011). Fourth, the positive association between high levels of vitamin $\mathrm{D}$ at birth and total and inhalant allergenspecific IgE may be attributable to a different mechanism (Wittke et al., 2004).

\section{Implications for practice}

This study suggests the opportunity for early intervention in young children with vitamin $\mathrm{D}$, especially those with vitamin D deficiency $(<20 \mathrm{ng} / \mathrm{mL})$. Interestingly, supplementation with vitamin D seems to lack therapeutic effect. Freishtat et al. (2010) found that participants with severe COPD cannot obtain any additional effect of vitamin D in addition to regular treatment. Thus, these findings may help guide the design and supplement dose in future trials. More studies in other chronic diseases and allergy diseases are needed to further explore the need and safety in recommending these higher doses of vitamin $\mathrm{D}$ to obtain potential beneficial effects.

\section{CONCLUSION}

The prevalence of vitamin D insufficiency and deficiency was different between cases and control subjects in asthma or COPD, although the quality of the available evidence was low to moderate at best. Due to the observational study design and the heterogeneity between the studies, the results remain difficult to interpret. More clinical trials are necessary to resolve the uncertainties about the association between vitamin D deficiency and COPD.

\section{Conflicts of interest}

The authors declare no conflict of interest.

\section{REFERENCES}

Alyasin S, Momen T, Kashef S, Alipour A, et al. (2011). The relationship between serum 25 hydroxy vitamin D levels and asthma in children. Allergy Asthma Immunol. Res. 3: 251-255.

Bener A, Ehlayel MS, Tulic MK and Hamid Q (2012). Vitamin D deficiency as a strong predictor of asthma in children. Int. Arch. Allergy Immunol. 157: 168-175.

Boyan BD, Wong KL, Fang M and Schwartz Z (2007). $1 \alpha, 25(\mathrm{OH})_{2} \mathrm{D} 3$ is an autocrine regulator of extracellular matrix turnover and growth factor release via ERp60 activated matrix vesicle metalloproteinases. J. Steroid Biochem. Mol. Biol. 103: 467-472.

Brehm JM, Schuemann B, Fuhlbrigge AL, Hollis BW, et al. (2010). Serum vitamin D levels and severe asthma exacerbations in the Childhood Asthma Management Program Study. J. Allergy Clin. Immunol. 126: 52-58.

Brehm JM, Acosta-Perez E, Klei L, Roeder K, et al. (2012). Vitamin D insufficiency and severe asthma exacerbations in Puerto Rican children. Am. J. Respir. Crit. Care Med. 186: 140-146.

Camargo CA Jr, Ingham T, Wickens K, Thadhani R, et al. (2011). Cord-blood 25-hydroxyvitamin D levels and risk of respiratory infection, wheezing, and asthma. Pediatrics 127: e180-e187.

Chinellato I, Piazza M, Sandri M, Peroni D, et al. (2011). Vitamin D serum levels and markers of asthma control in Italian children. J. Pediatr. 158: 437-441.

Contoli M, Baraldo S, Marku B, Casolari P, et al. (2010). Fixed airflow obstruction due to asthma or chronic obstructive 
pulmonary disease: 5-year follow-up. J. Allergy Clin. Immunol. 125: 830-837.

DerSimonian R and Laird N (1986). Meta-analysis in clinical trials. Control. Clin. Trials 7: 177-188.

Egger M, Davey SG, Schneider M and Minder C (1997). Bias in meta-analysis detected by a simple, graphical test. $B M J$ 315: 629-634.

Freishtat RJ, Iqbal SF, Pillai DK, Klein CJ, et al. (2010). High prevalence of vitamin D deficiency among inner-city African American youth with asthma in Washington, DC. J. Pediatr. 156: 948-952.

Garland C, Shekelle RB, Barrett-Connor E, Criqui MH, et al. (1985). Dietary vitamin D and calcium and risk of colorectal cancer: a 19-year prospective study in men. Lancet 1: 307-309.

Goleva E, Searing DA, Jackson LP, Richers BN, et al. (2012). Steroid requirements and immune associations with vitamin $\mathrm{D}$ are stronger in children than adults with asthma. J. Allergy Clin. Immunol. 129: 1243-1251.

Gorman S, Judge MA, Burchell JT, Turner DJ, et al. (2010). 1,25-Dihydroxyvitamin D3 enhances the ability of transferred CD4+ CD25+ cells to modulate T helper type 2-driven asthmatic responses. Immunology 130: 181-192.

Gupta A, Sjoukes A, Richards D, Banya W, et al. (2011). Relationship between serum vitamin D, disease severity, and airway remodeling in children with asthma. Am. J. Respir. Crit. Care Med. 184: 1342-1349.

Hewison M (2012). Vitamin D and immune function: autocrine, paracrine or endocrine? Scand. J. Clin. Lab. Invest. Suppl. 243: 92-102.

Higgins JP, Thompson SG, Deeks JJ and Altman DG (2003). Measuring inconsistency in meta-analyses. BMJ 327: 557-560.

Krobtrakulchai W, Praikanahok J and Jirapongsananuruk O (2012). The effect of vitamin D status on pediatric asthma in a university hospital, Thailand. J. Allergy Clin. Immunol. 129: AB78.

Lehouck A, Mathieu C, Carremans C, Baeke F, et al. (2012). High doses of vitamin D to reduce exacerbations in chronic obstructive pulmonary disease: a randomized trial. Ann. Intern. Med. 156: 105-114.

Li F, Peng M, Jiang L, Sun Q, et al. (2011). Vitamin D deficiency is associated with decreased lung function in Chinese adults with asthma. Respiration 81: 469-475.

Litonjua AA, Hollis BW, Schuemann BK, Celedon JC, et al. (2008). Low serum vitamin D levels are associated with increased asthma exacerbations among children using regular inhaled corticosteroids. J. Allergy Clin. Immunol. 121: S144-S244.

Masoli M, Fabian D, Holt S and Beasley R (2004). The global burden of asthma: executive summary of the GINA Dissemination Committee Report. Allergy 59: 469-478.

McGrath J (1999). Hypothesis: is low prenatal vitamin D a risk-modifying factor for schizophrenia? Schizophr. Res. 40: 173-177.

McGrath J, Saari K, Hakko H, Jokelainen J, et al. (2004). Vitamin D supplementation during the first year of life and risk of schizophrenia: a Finnish Birth Cohort Study. Schizophr. Res. 67: 237-245.

Ooi JH, Chen J and Cantorna MT (2012). Vitamin D regulation of immune function in the gut: why do T cells have vitamin D receptors? Mol. Aspects Med. 33: 77-82.

Paul G, Brehm JM, Alcorn JF, Holguin F, et al. (2012). Vitamin D and asthma. Am. J. Respir. Crit. Care Med. 185: 124-132.

Persson LJ, Aanerud M, Hiemstra PS, Hardie JA, et al. (2012). Chronic obstructive pulmonary disease is associated with low levels of vitamin D. PLoS One 7: e38934.

Rothers J, Wright AL, Stern DA, Halonen M, et al. (2011). Cord blood 25-hydroxyvitamin D levels are associated with aeroallergen sensitization in children from Tucson, Arizona. J. Allergy Clin. Immunol. 128: 1093-1099.

Schauber J and Gallo RL (2008). Vitamin D deficiency and asthma: not a strong link-yet. J. Allergy Clin. Immunol. 121: 782-783.

Schou AJ, Heuck C and Wolthers OD (2003). Does vitamin D administered to children with asthma treated with inhaled glucocorticoids affect short-term growth or bone turnover? Pediatr. Pulmonol. 36: 399-404.

Schwartz GG and Hulka BS (1990). Is vitamin D deficiency a risk factor for prostate cancer? (Hypothesis). Anticancer Res. 10: 1307-1311.

Shaheen SO, Jameson KA, Robinson SM, Boucher BJ, et al. (2011). Relationship of vitamin D status to adult lung function and COPD. Thorax 66: 692-698.

Urashima M, Segawa T, Okazaki M, Kurihara M, et al. (2010). Randomized trial of vitamin D supplementation to prevent seasonal influenza A in schoolchildren. Am. J. Clin. Nutr. 91: 1255-1260.

Wang TJ, Pencina MJ, Booth SL, Jacques PF, et al. (2008). Vitamin D deficiency and risk of cardiovascular disease. Circulation 117: 503-511.

Wittke A, Weaver V, Mahon BD, August A, et al. (2004). Vitamin D receptor-deficient mice fail to develop experimental allergic asthma. J. Immunol. 173: 3432-3436.

Wu AC, Tantisira K, Li L, Fuhlbrigge AL, et al. (2012). Effect of vitamin D and inhaled corticosteroid treatment on lung function in children. Am. J. Resp. Crit. Care Med. 186: 508-513.

Zasloff M (2006). Fighting infections with vitamin D. Nat. Med. 12: 388-390.

Zhou X, Han J, Song Y, Zhang J, et al. (2012). Serum levels of 25-hydroxyvitamin D, oral health and chronic obstructive pulmonary disease. J. Clin. Periodontol. 39: 350-356. 